\title{
Application of Strategic Decision Making to Design for Manufacture
}

\author{
Kristina Galuppo \\ School of Business, State University of New York at Oswego, Oswego, New York, United States
}

Email address:

kristina.galuppo@gmail.com

To cite this article:

Kristina Galuppo. Application of Strategic Decision Making to Design for Manufacture. American Journal of Operations Management and Information Systems. Vol. 4, No. 3, 2019, pp. 92-98. doi: 10.11648/j.ajomis.20190403.14

Received: June 15, 2019; Accepted: September 3, 2019; Published: September 16, 2019

\begin{abstract}
Design for manufacture connects the product design process directly with the manufacturing process. The implementation of this system can be basic and done without much care. Companies face common issues when using this system such as large discrepancies between the initial idea for a product and the final product offering. An emphasis of cost savings over all other values is an easy trap to fall into when using design for manufacture. Despite low production costs, a product that tested well with audiences can still fail if the cost cutting initiatives affected the final offering too heavily. The intent of this essay is to introduce strategic decision making systems into the process to illustrate how design for manufacture can be implemented and maintained to create a more fluid product development process without sacrificing other aspects of product development; such as quality of design or consumer value. A multiple criteria decision making system can be introduced to the process to help tighten the reigns on costs while still allowing consideration for other factors. Using these two systems together allows a company to save on costs without sacrificing sales due to low quality or loss of consumer confidence.
\end{abstract}

Keywords: Design for Manufacturing, DFM, Decision Making Systems, Strategic Decision Making, Product Supply Chain, Resource Management, Multiple Criteria Decision Making

\section{Introduction}

Decision making systems are an important part of every phase of the product development cycle. From concept development to manufacturing and distribution, there are decisions to be made that can affect the success of a product in the market. It is important to consider a wide variety of factors such as consumer value, cost, time to market, and public reception. Miscalculating any of these factors can lead to a failed product and create losses for the company. That is why it is important to have the proper decision making systems in place.

Bringing the proper decision making system into an existing framework requires analysis and care. By taking a closer look at the design for manufacture process we can determine where opportunities lie. Important decisions such as whether, and where, to outsource production as well as how to source materials used in production must be considered. Every option can affect the cost of production as well as the public response to the product. Ensuring there is a sound system in place for the decision making process is necessary to ensure the successful launch of a product as well as the wellbeing of the business in general.

Since the main purpose of design for manufacture is to reduce costs, we will apply relevant decision making systems to the manufacturing strategy with cost reduction in mind. The biggest area of opportunity exists within the implementation of a manufacturing strategy phase. We will discuss the application of a multiple criteria decision making system to the design for manufacture process and apply it directly to the selection of manufacturing models. We will also review the alternative of outsourcing rather than implementing complex decision making structures as a cost saving initiative.

Ultimately, applying a multiple criteria decision making system to the design for manufacture process allows decisions to be made using the greatest amount of quality information. This gives a company more control over the product development cycle which leads to greater cost savings. It also avoids the pitfalls of outsourcing that can cause company scandals, a loss of consumer confidence, and a lack of control over the manufacturing process. 
Consideration should be given to the multiple criteria decision making system application of design for manufacture as a real option for reducing costs in the manufacturing process.

\section{A Look at Design for Manufacture}

The manufacturing decision process begins during product development. Consideration must be taken for how the product will be manufactured before a concept can be finalized and accepted. A product that is developed for mass production has to conform to cost restraints or else it risks being a drain on a company's resources. This is done using a process known as Design for Manufacture (DFM), the process is also related to Design for Assembly and Design for Manufacture and Assembly. DFM is an extra set of steps included in the design process to ensure the product will conform to the company's manufacturing capabilities while reducing the cost of overall production. The 5 steps of DFM are to estimate the manufacturing costs, reduce the costs of components, reduce the costs of assembly, reduce the costs of supporting production, and consider the impact of DFM decisions on other factors [18].

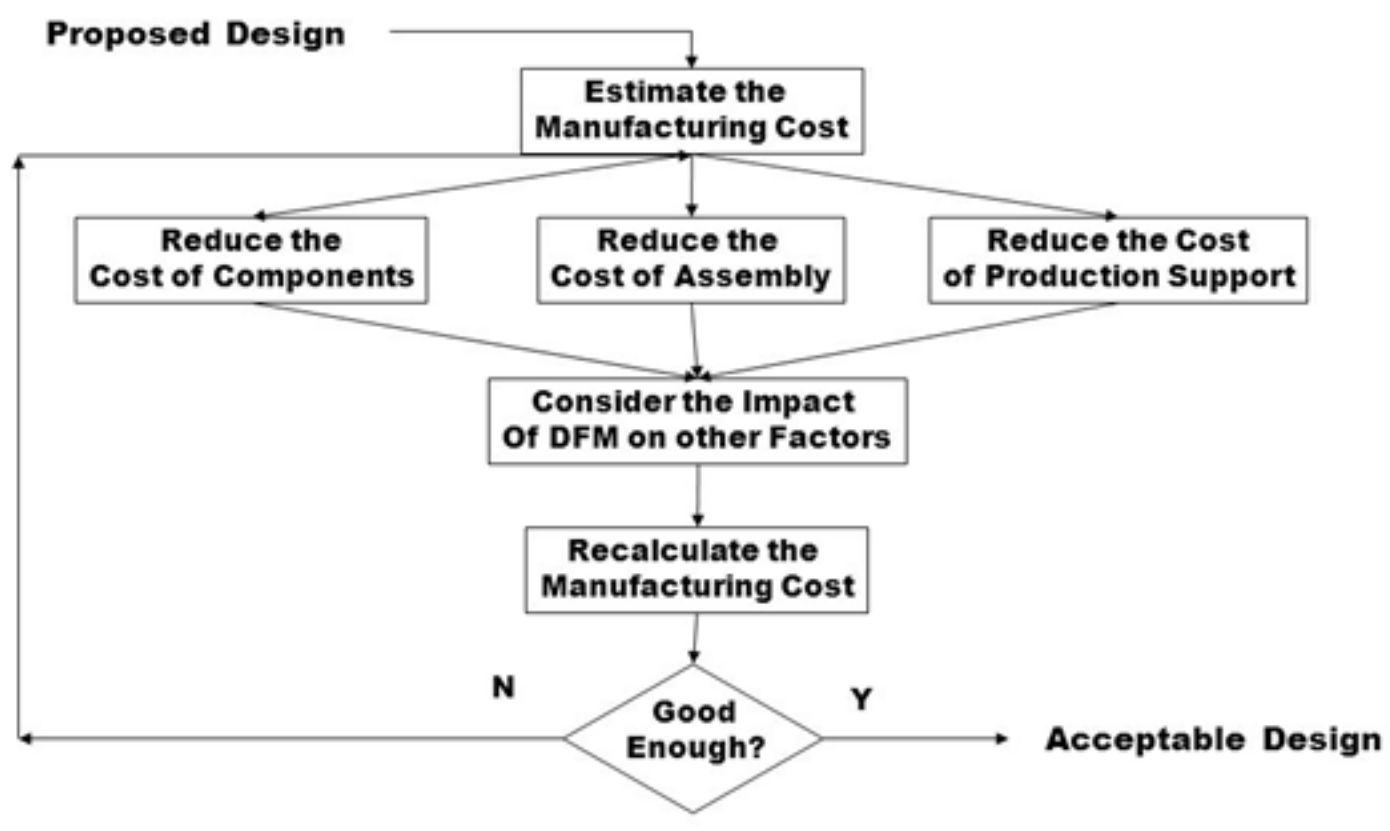

Figure 1. Design for Manufacture Flowchart [18].

The importance of cost reduction when considering the manufacture of a product is paramount, and it drives decisions that are made throughout the entire process. Using DFM to aid the decision process is a valuable way to reduce costs early on in the product development cycle. This is because design decisions make up about $70 \%$ of the cost of a product while only $20 \%$ are attributed to production decisions [1]. The methods used in DFM can also lead to innovative products as well as new innovations for supply chains and manufacturing facilities due to the extra focus put into the way the product is built. By bringing manufacturing decisions into the design process it is possible to reduce the total number of parts, develop a more modular design, standardize components across product offerings, design multi-functional and multi-use parts, design for ease of fabrication, decrease the use of fasteners, minimize assembly directions, maximize compliance, and minimize handling [1].

DFM's benefits are not equal in all industries. The system is best used by manufacturers whose products are more complex. Products that are simple may not be able to be simplified any further. This process was applied by BIC Corp. to try and reduce the manufacturing costs of their pen products; however, it was found that the products could not be simplified any further because the individual components could not be combined any further [3]. There are other disadvantages to using DFM that may make it difficult to implement in certain situations. There is greater scrutiny placed on a designer's work, so it may cause a more hostile environment if designers are not used to working in such conditions. There is also a greater emphasis on team development, so without proper team building there could be delays caused by disagreements between team members. The impact of these problems can be minimized with the use of software that has been adapted to assist with the DFM process. These four systems, computer-aided design (CAD) expert, automated assembly expert, manual assembly expert, and design analysis expert, have been shown to be able to work together to help automate the process and reduce the amount of human involvement in the decision process [16].

\section{How to Incorporate Strategic Decision Making in DFM}

In order to bring strategic decision making into the design and manufacturing process, decision makers need to become 
more deliberate and thoughtful in their approach. Solving complex problems can be too difficult for people to handle in their entirety, so they tend to cut down on the complexity by applying approximation ideas to problems they are incapable of reasoning through exactly [19]. One way to do this is by using an activity called organizational sensemaking. Sensemaking is a largely social process because it requires that the members of the organization interpret their environment by the interactions that they have with others. It allows people to handle the uncertainty that comes with complex problems by creating "rational accounts of the world that enable action [12]." Although sensemaking won't necessarily lead to any breakthrough decisions during the design process, it does explain the behavior of the people working together within an organization. In that vein, critical sensemaking can be used to understand behaviors exhibited within the design process and be used for the successful implementation of DFM.

When dealing with the implementation of a new system, it is important to understand how people analyze and react to their environment. In order to do that, it is necessary to be critical of the sensemaking process. "Critical sensemaking provides a framework for understanding how individuals make sense of their environments at a local level while acknowledging power relations in the broader societal context [13]." Using critical sensemaking allows organizers to observe how designers and their teams respond to each other as well as the rules that are implemented to constrain their activities. An analysis of their behavior will allow the company to enact an acceptable level of constraint and to intervene in the social process to foster the smooth transition into the team-based system of DFM.

Once any inter-team conflict is ironed out, ensuring that the decisions made using DFM are rational is the next step. Strategic decisions are made intentionally and with the effort to create a rational outcome. These decisions are generally important ones that relate to taking action, committing resources, or setting a precedent [7]. In the case of DFM, decisions are being made to minimize the commitment of resources. The decisions made can also set a precedent for all design and manufacturing decisions made going forward, so taking a strategic approach is necessary. To ensure rationality, the feelings and intuition of the designers working on the project are likely to be overridden. The process becomes more quantitative when manufacturing costs are taken into account so early on in the process.

Identifying whether decisions are being made based on concrete data and rational thought or whether they are being made intuitively must be done to ensure a strategic decision is being made. A major issue with using intuition within the decision making process is that it can be done with a high level of confidence despite a lack of strong evidence to support a desirable outcome [10]. Separating intuition from the design phase of a new product, however, can be incredibly difficult since it is an important part of new product innovation. During the concept generation phase, the goal is to identify and build from an unfulfilled customer need, which is not always known to the customer [18]. Designers need to fill in the gaps to identify a need that the customer may not even realize is unfulfilled, and intuition plays a part in that process.

Despite its importance early on in the design process, when moving out of the concept generation phase intuition should be removed from the equation. Intuition is best used on problems that are less structured, such as concept development, in order to speed up the process [4]. When focusing on reducing costs however, the decisions are highly structured, and data should be readily available. Refocusing the mindset of the team from intuitive to data driven, though, might prove difficult. Having a concrete decision system in place will help to ensure strategic thought is being used and that intuition is left behind.

\section{Implementing a Manufacturing Strategy}

There are numerous decisions that need to be made within the manufacturing process: determining the method for manufacture, where to locate the manufacturing facility, and what materials to use and how to source them. These along with other decisions make the process ideal for decision making systems to be used. Many of the decisions will be made based on the product that is being produced and, in order to increase effectiveness, they should be made as early as possible. The goals of the decisions made during the manufacturing process are aligned with the general goals of DFM: to reduce manufacturing costs. Incorporating a manufacturing strategy into the company's efforts should make the DFM process clearer and more fluid for everyone involved.

Pursuing a proper manufacturing strategy will help to make any decision regarding manufacturing much easier. The overall manufacturing strategy is made up of two separate principal strategies: manufacturing-task strategy and manufacturing-choice strategy. The former is defined as using an improvement task which will set a standard for the capabilities that should be focused on such as cost, flexibility, and quality, while the latter is defined as the "adoption of the suitable manufacturing technologies and practices, such as just in time, total quality management, or manufacturing resource planning, etc [8]." The process of defining improvement tasks is highly useful when it comes to ranking alternatives in the decision making process. The sooner this is defined during the design process the better, so that not only does the manufacturing model conform to the strategy, but so too does the product itself. These improvement tasks will also be referred to as value dimensions which will be discussed in more detail later on. The manufacturing-choice strategy helps decision makers to focus in on what type of technologies and practices to employ. Using this strategy means taking advantage of new and existing ideologies to define production capabilities and create a natural order within the manufacturing facility. Focusing on these two 
strategies will help when developing the general manufacturing strategy.

The formulation of the manufacturing strategy should be a process that is consulted regularly and allowed to evolve with the changing environment and company direction. A loose set of rules can be followed to ensure the strategy is known, followed, and not allowed to become stale. First a concrete manufacturing strategy will need to be developed and maintained. Ensure that there is no ambiguity and that it is well understood and implemented. This strategy should be shared with every functional department that is involved in the product development process. Even those not directly involved in the manufacture of the product or decisions made regarding strategy should be familiar with it. This will help to facilitate DFM throughout the entire development process. The manufacturing strategy must be aligned with the corporate strategy. This may require a group effort to achieve, but not following this rule could get the company into trouble down the line if those at the top are oblivious to the misalignment of strategies. The strategy should be reviewed and revised periodically to ensure that it remains in line with the company strategy and keeps up to date with current technologies. Failing to do so could lead to an out of date system that is expensive to maintain and falls behind competing firms. Competitors can take advantage of this by pricing the company out of the market. A good manufacturing strategy should also affect other functional strategies within the company, just as it is affected by them. Finally, long-term manufacturing capabilities should be developed congruent with the overall strategy. Following these rules will help to create a flexible strategy that fits in with the company and will create a more cohesive development unit [11].

Formulating a solid manufacturing strategy will set the groundwork for implementing DFM, but it is not the only tool that should be used when making decisions regarding the ultimate design and manufacture of a product. Decision making systems will still need to be set in place for making complex decisions during the product design process. One such system that is especially relevant to the many moving parts of the product development process is the multiple criteria decision making system.

\subsection{Using a Multiple Criteria Decision Making System}

The main goal of DFM is to reduce the costs of manufacturing, however costs should not be lowered by any means necessary. There are other things that must be considered when looking for ways to create a low-cost manufacturing strategy. For instance, costs should not be cut if it means sacrificing value. If the value of the product is lost during manufacture then a reduced cost won't mean much when the product fails. It is also important to consider the company's mission when making cost reducing decisions. Any decision that creates an outcome that is counter to the company and manufacturing strategies should be avoided, even if it fulfills the goal of lowering costs. Due to these extra considerations that must be taken, using a multiple criteria decision making (MCDM) system is suggested. An MCDM approach allows for the consideration of multiple attributes and creates a system for evaluating each alternative in order to choose the best one [13]. So instead of simply allowing a choice based on the lowest cost alternative, multiple factors will be weighed against one another to create the most optimal decision based on multiple inputs. Likely inputs, aside from cost, include consumer value, government regulations, and company issued quality standards.

When ranking and choosing from alternatives created within the MCDM process, a standardized method must be used. This will give meaning to the process and create consistent rankings across various different alternatives. One option is the multiattribute utility theory (MAUT). The purpose of MAUT is to "help decision makers formalize their priorities and make calculated tradeoffs between disparate attributes [which permits] a more effective, and consistent, maximization of subjective values [17]." The process helps to convert subjective values into concrete values by assigning a value to each alternative and weights to each attribute. Each option has relevance to the attributes by which they are measured, also known as the value dimensions. By giving a value to the alternatives as they correspond to the attributes they are being weighed against, the decision becomes a quantitative one. Using a weighted sum of the value dimensions will yield the overall utility of the option [17].

The importance of the attributes used will determine their weight. As an example, if the company values low cost as its most important goal then the cost attribute will have a high weight, whereas if customer value is not considered important it will receive a low weight. Once the value dimensions of the alternative is totaled up, those with greater cost savings will have a higher ranking than those with greater customer value since the company defined its cost attribute as having a greater utility. As more attributes are introduced into the equation, the decision will become more complex, which is why having a definitive ranking system helps to simplify the decision. As discussed earlier, decision makers are unable to process highly complex issues, so they try to simplify the problem using approximation. Allowing this simplification will result in inconsistent decisions, and will not guarantee that the best possible decision is made.

Ensuring that decisions are made properly during the DFM process helps to set the stage for a smooth manufacturing process. If the goal has been focused on from the beginning then there will be less need for rework down the line if something does not line up during production. Applying a consistent approach from concept development to end product keeps the product development process from becoming disjointed and it also brings together teams of people that may not normally work together. The added synergy could lead to new breakthroughs and innovative ways to bring the product to life during production. Once the design team passes their work onto the manufacturing team it will be easier to incorporate the ideas into the more concrete processes of fabrication and assembly. 


\subsection{Selecting a Manufacturing Model}

There are different models that can be used by corporations when they are determining how best to assemble their products. These models have different focuses and can affect the outcome of the final product. Some products are better developed using different types of manufacturing models, so it is important to ensure that the correct model is chosen for optimum development. It is also possible to design a product based on the manufacturing model a company is using, which is why implementing DFM can be greatly helpful for a company that relies on regular product releases. DFM allows the company to take their available resources into consideration early on in the process and can help to take advantage of existing facilities. If these facilities do not already exist however, this decision can affect the direction of the company for all future product offerings, so it should be done right the first time.

If one is not already in place, a manufacturing model can be chosen prior to, during, or after the design process depending on the implementation of DFM. Sometimes a model is easily found based on the type of product that is considered for development. A system such as the flexible manufacturing system, which is designed to be able to handle mass customization, is an obvious direction to take if the company is determined to produce a small quantity of unique products while still maintaining a low cost strategy [6]. However, not every decision is so straight forward, so we can utilize the MCDM method discussed previously. This method is flexible, and can be used when considering product specifications and options for the manufacture of parts, and also when determining which manufacturing model to use.

One disadvantage of using MCDM is that it doesn't account for uncertainty within the model. Using the attributes to weigh and rank the different alternatives only accounts for known problems that the finished product may face once it reaches completion. Things like public reception, which can be predicted to some extent based on historical data, are largely uncertain variables. If the public has a certain expectation of complexity, then too much simplification during the manufacturing process can cause problems, even if it was the result of an alternative that had the highest overall utility. If uncertain variables are of great concern, then scenario planning may be utilized. The idea behind scenario planning is to identify a set of possible future scenarios that describe the behavior of the main uncertainties that surround the problem. These scenarios create a story of what could happen in the future and allow for exploration of how alternate methods of manufacture would fair under the same circumstances [15]. It will help to map out the unknowns, reduce surprises during manufacture, and could also be used to develop contingencies should the least likely scenario occur.

Scenario planning is a great way of navigating uncertainty when utilizing DFM, however, a more technical method of minimizing uncertainty may be desired when it comes to selecting which manufacturing model to use. This is especially important as the decision could limit the scope of products the company is able to offer in the long term. One option when working with MCDM is to use a grey based approach to handle the uncertain elements that exist. Introducing grey numbers into the MCDM when trying to account for uncertainty can help to make decisions in a difficult to predict environment. Grey numbers are "usually represented as a closed interval or a discrete set of numbers [20]." This allows for a less defined variable to be used when weighing alternatives. If uncertain attributes exist they will not need to be excluded when using a grey based approach. Using this approach requires more effort, along with a bit of calculus, to create the grey decision matrix and ultimately determine the grey possibility value. However, using this method will allow uncertainty to be minimized within the final decision if the goal is to find the most reliable method. The grey possibility value measures the uncertainty within the decision, meaning that a lower value is ideal, whereas a higher value conveys a greater level of uncertainty [9].

When choosing a manufacturing model reducing uncertainty is necessary to ensure that investment is directed in the proper direction. Both scenario planning and a grey based MCDM system offer ways to account for, and minimize, uncertainty. Companies should keep in mind that both options require a greater amount of thought and care be added to the decision process. This means extra time spent during or before the design process in weighing alternatives and can delay the time it takes to bring a concept to development. If speed to market is highly valued, it may be easier to outsource the problem instead of analyze it. By allowing the outsourcing of manufacturing the company can spend fewer resources choosing and developing their own manufacturing method, though this choice is not always well received by the public. The decision process should not be lost in determining whether or not to outsource the manufacturing process.

\subsection{To Outsource or to Not}

If a company is not up to the task of creating its own manufacturing facilities or maintaining an in depth manufacturing strategy, outsourcing is an option. When a company outsources its manufacturing, it is utilizing another firm or other firms to perform value-creating activities that may or may not have previously been handled in house. Outsourcing tends to be associated closely with offshoring, which occurs when a company moves an activity, such as manufacturing, to a foreign location [6]. A company can outsource its manufacturing to another firm without moving it overseas, or it can choose to pursue the offshoring option if cost reductions are attractive enough. There are benefits to doing so, just as there are risks.

When a company handles its own manufacturing it has greater control over the process. It can be sure that the manufacturing strategy is being implemented and keep a close eye on operations, however maintaining a manufacturing facility can be expensive. It is not ideal for a company that is maintaining a sharp focus in a different area 
of business. By outsourcing, the company does not have to worry about construction of facilities or maintenance costs. On the other hand, any scandals involving the manufacturer could cause trouble for the company in the form of irate customers and boycotts of the company's products. A well known instance where this has happened is with the technology company, Apple. The company has been bashed by the media in the past about the poor conditions of laborers in the Chinese manufacturing plants where Apple outsources the production of its products to [2]. This is an example of why the decision to outsource should not be made lightly, and deciding on where and who to outsource to is critically important.

One major reason to outsource manufacturing processes is that a company may be ill equipped to handle manufacturing products itself. If the manufacturing strategy is insufficient, then sinking money into the process is going to yield poor results. It is sometimes the case that, when outsourcing, costs are reduced not because of the decision to outsource, but rather the firms that were outsourced to have better operational control [5]. Companies that specialize in manufacturing are able to focus solely on the improvement of the process and create the greatest cost savings. This kind of specialization leads to the better implementation of manufacturing technologies and practices. If a company can operate at the same costs as the firm it is outsourcing to, then it should be able to realize the same cost savings on its own, however it may not be able to replicate the attention to operational control that the manufacturing firm can. In this case the rational choice would be to outsource.

By outsourcing, a company is essentially purchasing "outside expertise" rather than cultivating it from within and tapping into a greater pool of skills that were otherwise unavailable or difficult to obtain [21]. Although this is a tempting option, firms that engage in DFM are missing out on the greater control of having a smooth and connected process throughout the product development process. They can potentially create greater cost savings by being attentive and engaging in strict operational control, which is made possible under DFM. Should a firm engage in the strategic decision making processes required to pull off a successful DFM strategy then engaging in their own manufacturing process, or even working closely with a manufacturing firm, will result in the best level of implementation.

\section{Conclusion}

Firms looking to implement DFM can benefit from greater cost savings as well as increased synergies and a more fluid product development process. By incorporating solid decision making systems, firms increase the effectiveness of their design processes as well. The MCDM process is ideal for handling the many inputs involved in DFM and offers a logical way to identify and weigh values important to the firm. By ranking alternatives based on their adherence to these values better decisions can be made than using human judgment, which can be subjective and results in non- standardized decisions being made. By incorporating methods such a grey based decision making and scenario planning, even uncertainty within the models can be limited or reduced. Outside firms can also be used to help the company navigate an unfamiliar environment and reduce the risk of miscalculating the variables used when choosing a manufacturing model. Outsourcing production will allow greater focus to be placed on the design process and could result in better implementation of DFM, but it could also create a more disjointed process. Closely monitoring these implementation methods allows a firm to have the greatest control over its product development process and reduces the chance for errors. By enhancing DFM with the decision making methods discussed above, a competitive advantage may be achieved.

\section{References}

[1] Chang, T.-C., Wysk, R. A., \& Wang, H.-P. (1998). Design for Manufacturing - Guidelines. In Computer-Aided Manufacturing, Second Edition (pp. 596-598). Prentice Hall.

[2] Clarke, T., \& Boersma, M. (2017). The Governance of Global Value Chains: Unresolved Human Rights, Environmental and Ethical Dilemmas in the Apple Supply Chain. Journal of Business Ethics, 143 (1), 111-131.

[3] Constance, J. (1992). DFMA: Learning to Design for Manufacture And Assembly. Mechanical Engineering, 114 (5), 70-74.

[4] Dayan, M., \& Elbanna, S. (2011). Antecedents of Team Intuition and Its Impact on the Success of New Product Development Projects. The Journal of Product Innovation Management, 28 (s1), 159-174.

[5] Dekkers, R. (2011). Impact of Strategic Decision Making for Outsourcing on Managing Manufacturing. International Journal of Operations \& Production Management, 31 (9), 935-965. Retrieved from ABI/INFORM Global.

[6] Dess, G. G., McNamara, G., \& Eisner, A. B. (2016). Strategic Management: Creating Competitive Advantages, Eighth Edition. New York: McGraw-Hill Education.

[7] Eisenhardt, K. M., \& Zbaraki, M. J. (1992). Strategic Decision Making. Strategic Management Journal, 13, 17-37.

[8] Hau-Nung, L. (2002). A Research in Manufacturing Strategy and Competitiveness: Models and Practices (Ph.D. Thesis). The Hong Kong Polytechnic University, Hong Kong.

[9] Ji Shukla, O., Soni, G., \& Anand, G. (n.d.). An Application of Grey Based Decision Making Approach for the Selection of Manufacturing System. Grey Systems, 4 (3), 447-462. Retrieved from ABI/INFORM Global.

[10] Kahneman, D. (2011). Thinking, Fast and Slow. New York: Farrar, Straus and Giroux.

[11] Lee, W., Rhee, S.-K., \& Oh, J. (2014). The Relationships Between Manufacturing Strategy Process, ManufacturingMarketing Integration, and Plant Performance: An Empirical Study of Korean Manufacturers. Operations Management Research, 7 (3-4), 117-133. 
[12] Maitlis, S. (2005). The Social Processes of Organizational Sensemaking. Academy of Management Journal, 48 (1), 21-49.

[13] Malkooti, B. (2011). Systematic Decision Process for Intelligent Decision Making. Retrieved from ABI/INFORM Global.

[14] Mills, J. H., Thurlow, A., \& Mills, A. J. (2010). Making Sense of Sensemaking: The Critical Sensemaking Approach. Qualitative Research in Organizations and Management, 5 (2), 182-195. Retrieved from ABI/INFORM Global.

[15] Montibeller, G., \& Franco, L. (2011). Raising the Bar: Strategice Multi-Criteria Decision Analysis. The Journal of the Operational Research Society, 62 (5), 855-867.

[16] Sanders, D., Tan, Y. C., Rogers, I., \& Tewkesbury, G. E. (2009). An Expert System for Automatic Design-for-Assembly. Assembly Automation, 29 (4), 378-388.

[17] Shafir, E., \& LeBoeuf, R. A. (2004). Context and Conflict in
Multiattribute Choice. In D. J. Koehler, \& N. Harvey, Blackwell Handbook for Judgment \& Decision Making (pp. 341-359). Malden: Blackwell Publishing.

[18] Ulrich, K. T., \& Eppinger, S. D. (2016). Product Design and Development, Sixth Edition. New York: McGraw Hill Education.

[19] Weston, R. H. (2012). Model Driven Integrated DecisionMaking in Manufacturing Enterprises. Advances in Decusion Sciences. doi: 10.1155/2012/328349.

[20] Yang, Y., \& Liu, S.-f. (2011). Reliability of Operations of Grey Numbers Using Kernels. Grey Systems, 1 (1), 57-71.

[21] Zutshi, A., Creed, A., Sohal, A. S., \& Wood, G. (2012). Consideration of Selflessness and Self-Interest in Outsourcing Decisions. European Business Review, 24 (3), 287-303. Retrieved from ABI/INFORM Global. 